\title{
ESTABLISHMENT, PERSISTENCE, AND INTROGRESSION OF ENTOMOPATHOGENIC NEMATODES IN A FOREST ECOSYSTEM
}

\author{
A. B. Dillon, ${ }^{1}$ A. N. Rolston, C. V. Meade, M. J. Downes, and C. T. Griffin \\ Department of Biology and Institute of Bioengineering and Agroecology, NUI Maynooth, Maynooth, County Kildare, Ireland
}

\begin{abstract}
Entomopathogenic nematodes (EPN) are currently marketed worldwide for use in inundative biological control, where the applied natural enemy population (rather than its offspring) is expected to reduce insect numbers. Unlike classical biological control, in inundative control natural enemy establishment is not crucial in order to achieve pest suppression. Field trials in Irish forestry provided the opportunity to test predictions regarding the establishment of two exotic (Steinernema carpocapsae and Heterorhabditis megidis) and two indigenous (Steinernema feltiae and Heterorhabditis downesi) species. Nematodes were inundatively applied to pine stumps to control populations of pine weevil, Hylobius abietis, on three clearcut sites, and their persistence and spread monitored for up to five years. All species were recovered three years after application but only $S$. feltiae was recovered in years 4 and 5 . Limited horizontal dispersal to $20 \mathrm{~cm}$ (but not $100 \mathrm{~cm}$ ) was observed, but the majority of nematodes were recovered close to the area of application. Steinernema feltiae was also recovered from nearby stumps to which it had not been applied, indicating possible phoretic dispersal by weevils or other stump-associated fauna. EPN were not recovered from stumps outside the treated area, suggesting that such dispersal is quite localized. Two strains of S. feltiae (Irish and exotic) were applied. Amplified fragment length polymorphism (AFLP) analysis on 11 populations isolated from soil four years later showed that all had a much closer affinity to the applied Irish strain, suggesting persistence of this genotype and extinction of the exotic one. Some strains were clustered close together, and this is interpreted in the light of possible population genetic scenarios. The findings from the field study confirm predictions based on background knowledge of the species and demonstrate the importance of mediumterm studies, as a 3-year study would have overestimated the risk of establishment of exotic species. Short-term persistence and spread of S. carpocapsae, S. feltiae, and H. downesi was also studied in pine forest mesocosms. Similar trends to field results, such as limited horizontal dispersal, even vertical distribution, and more abundant recovery of $S$. feltiae than of other species, point to the utility of mesocosm studies as a predictive tool.
\end{abstract}

Key words: AFLP; alien species; exotic biological control agent; Heterorhabditis; hybridization; Hylobius; Steinernema.

\section{INTRODUCTION}

Biological control has generally been perceived to be less disruptive to native animals than broadscale use of insecticides, which in many cases are not selective to the target species (DeBach and Rosen 1991). Potential risks associated with the use of exotic biological control agents (BCAs) in classical biological control have been comprehensively reviewed (Simberloff and Stiling 1996, Louda et al. 2003). It is clear that numerous classical biological control introductions have adversely affected nontarget native species (Louda et al. 2003). In the case of classical biological control, natural enemies are chosen for their potential to establish and spread. In contrast, in inundative biological control programs large numbers of natural enemies are released with a view to achieving rapid reduction in the pest population; long-

Manuscript received 21 June 2007; revised 28 September 2007; accepted 5 November 2007. Corresponding Editor: S. K. Collinge.

${ }^{1}$ E-mail: aoifebdillon@gmail.com term establishment is not sought (e.g., control of pests in glasshouses such as the use of Encarsia formosa Gahan against whiteflies and Phytoseiulus persimilis AthiasHenriot against two spotted spider mites). While this makes release of exotic BCAs in inundative control programs inherently less risky than classical introductions, such releases also need careful consideration (van Lenteren et al. 2003). In order to evaluate whether exotic or indigenous BCAs pose a threat to nontarget organisms, our most powerful tools are the use of background knowledge (Thomas and Willis 1998) and post-release studies.

Entomopathogenic nematodes (EPN) of the genera Steinernema and Heterorhabditis (Nematoda: Rhabditida) are insect parasites, whose pathogenicity is partly due to their symbiotic association with bacteria of the genera Xenorhabdus and Photorhabdus, respectively (Forst et al. 1997). EPN were first applied to control Japanese beetles in the 1930s, and since the 1980s have been applied in inundative biological control programs to control several important insect pests (Georgis et al. 
2006). The infective juveniles (IJs) actively seek out insects in the soil. The IJs enter the insect through the natural openings and, in the case of Heterorhabditis, through the cuticle. In the insect hemocoel, the IJs release their symbiotic bacteria from their gut, resulting in insect death. Following development to adult stages, reproduction produces thousands of fresh IJs, which emerge into the soil from the host insect cadaver as the resources become exhausted.

EPN possess specific biological and ecological characteristics that make their use in biological control exceptionally safe, though it is recommended that the release of exotic species should be regulated (Ehlers and Hokkanen 1996, Organisation for Economic Co-operation and Development 2003). As EPN are marketed worldwide, the application of exotic strains of indigenous species must be considered a relatively common occurrence. Van Lenteren et al. (2003) proposed a risk assessment methodology for the evaluation of inundative biological control agents, using five critical ecological factors: (1) establishment; (2) dispersal; (3) host range; (4) direct effects of released organisms on other organisms in the ecosystem; and (5) indirect effects, such as competition and hybridization. A risk factor can be calculated based on the likelihood and magnitude of risk for each of these factors. Using this methodology, van Lenteren et al. (2003) concluded that application of Steinernema feltiae Filipjev in open fields in Finland constitutes an intermediate risk. High-risk factors include the nematode's broad host range and the fact that establishment was considered likely. Although the probabilities of direct and indirect effects were high, the magnitudes of these effects were considered moderate and minor, respectively. Overall, the limited dispersal capacities strongly reduced the overall risk value of $S$. feltiae. While background information can allow predictions to be made, whether applied nematodes will establish in a specific ecosystem, and whether they will have negative nontarget effects, can only be conclusively validated by post-release studies.

EPN biodiversity in Ireland is relatively low. Only three species have been recovered to date: Heterorhabditis downesi Stock, Griffin and Burnell, Steinernema affine Bovien, and S. feltiae (Blackshaw 1988, Griffin et al. 1991, 1994, Dillon 2003). Field trials of several species of EPN against the large pine weevil, Hylobius abietis L. (Coleoptera: Curculionidae; Dillon et al. 2006), provided a rare opportunity to test predictions regarding the establishment of exotic species of EPN based on background knowledge of their ecology.

Under natural forest conditions, H. abietis breed in damaged or fallen trees and feed on the crowns of mature trees. In intensively managed coniferous forests, female weevils lay their eggs on or near recently felled coniferous stumps. Neonate larvae migrate under the bark of the stump, where they develop to adults in two to four years (Norlander et al. 1997, Leather et al. 1999). Stumps only remain suitable for $H$. abietis development for up to five years after felling (Bakke and Lekander 1965). In the absence of alternative hosts, these introduced natural enemies would be driven to extinction within the site (Swihart et al. 2001, Ryall and Fahrig 2006). However, as stumps become unsuitable for H. abietis development, they are colonized by other coleopterans (such as Elateridae), as well as hymenopterans and dipterans (Wallace 1954, Elton et al. 1964, Wainhouse et al. 2001), all of which are potential hosts for EPN.

Four species of EPN were tested in the pine weevil trials. Of these, two are exotic to Ireland (H. megidis Poinar, Jackson and Klein and S. carpocapsae Weiser) and two are indigenous (H. downesi and S. feltiae). Based on the literature, not all of the species tested can be considered environmentally suitable to cool Irish temperatures and the peat soils that are typically used for coniferous forest plantations in Ireland and the UK. Although $H$. downesi is an indigenous species in Ireland, it has only ever been found in very sandy soils at the coastal fringe, where it is common (Griffin et al. 1991, 1994), so therefore can be considered exotic to this soil type. The non-indigenous species $H$. megidis also exhibits a preference for sandy coastal sites (Hominick 2002). In Britain, H. megidis was recovered only once from the south coast of England (Hominick 2002), despite widespread sampling of suitable habitats (Griffin et al. 1994), suggesting that it may be limited by a need for warm conditions. Soil type, and possibly temperature requirements, therefore make establishment of $H$. megidis in an Irish forest ecosystem unlikely. Similarly, the other exotic species $S$. carpocapsae has only once been recovered in Britain and is rare in Northern Europe (Hominick 2002). In the most extensive survey of EPN to date, of the 584 EPN specimens recovered from 1193 sites in Germany, only 1 was identified as $S$. carpocapsae (Sturhan 1999). In contrast, S. feltiae is one of the dominant EPN species in Northern Europe and has frequently been recovered from forest soils (Hominick 2002), including in Ireland where it was recovered from $9 \%$ of sites with standing coniferous forest and $7 \%$ of sites where conifers had been clearcut (Dillon 2003). Based on this background knowledge of the biogeography and habitat preferences of the test species, we predict that $S$. carpocapsae, H. megidis, and $H$. downesi will not persist in the clearcut forest ecosystem, but that applied strains of $S$. feltiae may do so.

While both species of Heterorhabditis appear to be coleopteran specialists, S. feltiae and S. carpocapsae exhibit broad host ranges (Peters 1996). Although numbers of applied EPN typically decline rapidly following application (Smits 1996), each of the four species of EPN tested can develop in Coleoptera (Peters 1996, Hominick 2002; M. R. Enright, personal communication) including pine weevil (Dillon 2003), so we expect localized persistence of EPN populations as long as abundant suitable hosts remain available. 
Indirect effects such as competitive displacement and/or hybridization are possible risks associated with the introduction of exotic species, including EPN (Ellstrand et al. 1999, van Lenteren et al. 2003, Weigel et al. 2003). Strains of a species may differ in virulence, reproductive capacity, and environmental tolerance (Somasekhar et al. 2002b), and there is a risk that exotic strains might competitively displace native strains of the same species. Natural populations of EPN are typically patchy both in space and time making it difficult to assess the effects of extraneous factors on their abundance. In the present study, an exotic and indigenous strain of $S$. feltiae were both applied. As the latter was isolated from a clearcut conifer site we expect it to be genetically adapted to these conditions and therefore representative of the native EPN population of such sites. We used AFLP (amplified fragment length polymorphism) to identify $S$. feltiae strains recovered 48 months after application in order to quantify establishment of the exotic strain and/or hybridization between the exotic and indigenous $S$. feltiae strains. AFLP markers have been shown to be useful for analyzing inter- and intraspecific genetic diversity of a number of organisms including plants, insects, and fungi (Salvato et al. 2002, Tooley et al. 2002, Travis et al. 2004) and have recently been used to analyze populations of EPN (Rolston et al. 2006). As AFLP samples multiple loci simultaneously, it is ideally suited for the analysis of genetic variation and similarity in species with low genetic variability.

We had three objectives in this study: (1) to evaluate dispersal and persistence of $S$. carpocapsae, S. feltiae, and $H$. downesi in pine forest mesocosms in the absence of insect hosts; (2) to test our predictions on the persistence of the aforementioned nematode species and $H$. megidis on clearcut pine sites under natural conditions of climate and host availability; and (3) to evaluate the extent to which an exotic $S$. feltiae strain could competitively displace and/or hybridize with a native strain of the same species.

\section{Methods}

\section{Nematodes}

The origin of the nematodes used in this study is given in Table 1. For the mesocosm experiment, all of the nematodes tested (S. carpocapsae All strain, S. feltiae 4CFMO, and $H$. downesi $\mathrm{K} 122$ ) were produced in vivo in Galleria mellonella L. (Woodring and Kaya 1988). Harvested IJs were washed by sedimentation in three changes of tap water and stored for up to a week at $9^{\circ} \mathrm{C}$. For the field studies, commercially produced $S$. carpocapsae All strain, S. feltiae EN02, and H. megidis were supplied on an inert carrier in a wettable powder formulation. The strain of $H$. megidis used was UK211 in 2001 (site 1) and NL-HF85 in 2002 (site 2). Steinernema feltiae 4CFMO and $H$. downesi $\mathrm{K} 122$ are not commercially available and were produced in vivo in G. mellonella.

\section{Persistence and dispersal of entomopathogenic nematodes in mesocosms}

Pine forest mesocosms were set up in plastic boxes (40 $\mathrm{cm}$ long $\times 25 \mathrm{~cm}$ high $\times 29 \mathrm{~cm}$ wide $)$. Each contained moss peat, a lodgepole pine (Pinus contorta Dougl.) log simulating a stump, and caged $H$. abietis larvae $15 \mathrm{~cm}$ from the log: a typical distance from the bole of the stump for these insects to be located (Brixey et al. 2006, Dillon et al. 2006). Early-instar larvae were collected from pine stumps, and stored with food at $9^{\circ} \mathrm{C}$ for up to one week before the experiment. A single weevil larva was placed between two discs of $P$. contorta bark $(5 \mathrm{~cm}$ diameter) in a plastic cylinder (height $2 \mathrm{~cm}$, diameter 5.5 $\mathrm{cm})$. Cylinders were loosely packed with moss peat and enclosed in wire mesh with a pore size of $1.5 \mathrm{~mm}$ to retain the insect. The base of each box was filled to a depth of $2 \mathrm{~cm}$ with peat. A $\log$ of pine (height $15 \mathrm{~cm}$; diameter 9-12 cm) and five caged weevils were placed in each box. The $\log$ was placed $5 \mathrm{~cm}$ from one end of the box, while the caged weevils, providing a stimulus for the nematodes, were arranged in a row $15 \mathrm{~cm}$ from the edge of the $\log$ and $1 \mathrm{~cm}$ apart. Peat was then added to the boxes, to give a total mass of $625 \mathrm{~g}$ of peat (with a depth of approximately $15 \mathrm{~cm}$ ). One liter of tap water was applied to each box as a surface drench using a watering can.

Nematodes were applied 24 hours later. Three nematode species ( $S$. carpocapsae All strain, S. feltiae 4CFMO, and $H$. downesi $\mathrm{K} 122$ ) were each applied at a dose of 0.5 million IJs/box, a dose comparable to the dose of 3.5 million IJs applied to tree stumps for suppression of $H$. abieits given the diameter of the log. A suspension containing $500000 \mathrm{IJs}$ in $10 \mathrm{~mL}$ of water was applied around each log. Eight blocks were set out in a randomized block design. Each block consisted of one box of each of the three treatments. In order to minimize the "edge effect" experimental blocks were bordered by boxes, each of which contained $625 \mathrm{~g}$ of peat, but no weevils or nematodes. The experiment was conducted in an unheated wooden prefabricated building. Soil temperature was recorded twice a week for the duration of the experiment. Boxes were weighed weekly and the water lost through evaporation was replaced.

The presence of nematodes in different parts of the box was detected by baiting peat samples with $G$. mellonella larvae (Bedding and Akhurst 1975). Infective juveniles are attracted to G. mellonella and baiting soil with $G$. mellonella is a widely used technique for detection and semi quantitative assessment of EPN populations. A box was sampled by taking three peat samples $\left(20 \mathrm{~cm}^{3}\right.$ each) at each of 12 locations: four distances from the edge of the $\log (0-5,6-10,11-15$, and $16-20 \mathrm{~cm}$ ), at each of three depths (upper, middle, lower); approximately $0-5,6-10$, and $11-15 \mathrm{~cm}$, respectively. The caged weevils were present in the lower 16-20 cm sample to encourage nematode dispersal. Each sample was baited with a single $G$. mellonella larva at $20^{\circ} \mathrm{C}$ for three days. The G. mellonella was removed and 
TABLE 1. Origin, supplier, and status in Ireland of the entomopathogenic nematode strains applied in the field studies.

\begin{tabular}{llll}
\hline \hline \multicolumn{1}{c}{ Species and strains } & \multicolumn{1}{c}{ Supplier } & Source of strain & \multicolumn{1}{c}{ Status in Ireland } \\
\hline Steinernema carpocapsae All strain & Koppert & USA & exotic species \\
Steinernema feltiae EN02 & E-Nema GmbH & Germany & indigenous species but exotic strain \\
Steinernema feltiae 4CFMO & NA & Ireland & indigenous species and strain \\
Heterorhabditis megidis UK211 & BeckerUnderwood & England & exotic species \\
Heterorhabditis megidis NL-HF85 & Koppert & Netherlands & exotic species \\
Heterorhabditis downesi K122 & NA & Ireland & indigenous species and strain \\
\hline
\end{tabular}

Note: NA in supplier column means that the strain is not commercially available and was produced by the researchers in vivo.

maintained at $20^{\circ} \mathrm{C}$ for a further two days, when nematode-induced mortality (based on the color and consistency of the cadaver) was recorded. Two to three days after nematode infection, G. mellonella cadavers infected with Steinernema spp. appear light brown (fawn) in color. Galleria mellonella cadavers infected with Heterorhabditis spp. turn a variety of colors including red, orange, and yellow. Samples were rebaited with a fresh $G$. mellonella and this was continued until all samples for a given location were negative for three successive baits.

Nematode distribution was assessed after 9, 14, and 19 weeks. Each mesocosm was sampled once only. Two (9 weeks) or three (14 and 19 weeks) replicate boxes per treatment were sampled on each date.

\section{Field sites and trials}

The persistence and spread of EPN was investigated at three sites in central Ireland, following their application to pine stumps ( $P$. contorta and Pinus sylvestris L.) in plantation forests to control H. abietis 18 months after felling. Soil on all sites was classified as deep peat. Sites 1 and 2 were located within the same forest, and approximately $75 \mathrm{~km}$ from site 3 . All sites were climatically similar. There was one field trial per site, with nematodes applied in 2001 (site 1), 2002 (site 2), or 2005 (site 3), as described in Dillon et al. (2006, 2007). Five nematode strains were applied on sites 1 and 2: H. downesi K122, S. carpocapsae All strain, S. feltiae 4CFMO, S. feltiae EN02, and either H. megidis UK211 (site 1), or H. megidis NL-HF85 (site 2). On site 3, only $H$. downesi K122, S. carpocapsae All strain, and $S$. feltiae 4CFMO were applied. A suspension of 3.5 million IJs in $500 \mathrm{~mL}$ of tap water was applied around each stump. Control stumps received $500 \mathrm{~mL}$ of tap water. The experiments were set out in a randomized block design. Each block contained 1 replicate (stump) of each treatment (six treatments on site 1 and 2, and four treatments on site 3 ). Nineteen (site 1) or 10 (sites 2 and 3) blocks were treated.

Two weeks prior to the inundative application of EPN, the presence of indigenous EPN on each site was assessed, by taking soil samples, which were returned to the laboratory and baited with G. mellonella larvae for seven days at $20^{\circ} \mathrm{C}$. Five samples $\left(100 \mathrm{~cm}^{3}\right.$ each) were taken on each of sites 1 and 2, while 50 samples $\left(25 \mathrm{~cm}^{3}\right.$ each) were taken on site 3. No native EPN were detected on any of the three sites before the field trials.

\section{Assessment of persistence and spread of entomopathogenic nematodes in the field}

The presence of EPN was detected by baiting soil cores with $G$. mellonella larvae. Cores were taken using sterile plastic $50 \mathrm{~mL}$ centrifuge tubes (diameter $3 \mathrm{~cm}$ ) at two depths. A core was first taken to a depth of approximately $5 \mathrm{~cm}$ ("upper"). A second core was taken in the same position at a depth of approximately 6-10 $\mathrm{cm}$ ("lower"). Samples were taken at the trunk $(0 \mathrm{~cm}$; where nematodes were applied) and $20 \mathrm{~cm}$ out from the trunk in order to investigate horizontal dispersal. Samples were taken at four aspects (north, south, east, and west) around the stump at the one-month sampling period, yielding a total of 16 cores per stump. These samples were taken immediately prior to the debarking of one-quarter of each stump, to investigate parasitism of the target pest $H$. abietis by applied nematodes. At all subsequent sampling times, samples were taken at only two aspects, from the side of the stump that had not been disturbed during debarking, yielding a total of eight cores per stump. Sampling around and at the stumps was performed until project end in 2006, which allowed for sampling 1, 12, 24, 36-37, and 48 months after nematode application on sites 1 and 2 and in addition, after 60 months on site 1 only. Site 3 which was treated in 2005 was sampled only after 1 and 12 months.

Occurrence of EPN away from stumps was investigated by taking cores approximately $1 \mathrm{~m}$ from the nearest stump at randomly chosen locations within the experimental area. An "upper" $(5 \mathrm{~cm})$ and "lower" (6-10 $\mathrm{cm})$ sample were taken at 100 locations throughout the site 12, 48, or 60 months (for sites 3, 2, and 1, respectively) after nematode application. Occurrence of EPN at stumps within the clearcut site but outside the experimental area was investigated by taking 19 samples at a distance of 1,5 , and $10 \mathrm{~m}$ from the edge of the 2-ha area of treated stumps on site 1 . At each location an "upper" and "lower" sample were taken $0 \mathrm{~cm}$ from bole of the stump. This was done 1, 12, 24, and 36 months after nematode application.

Soil samples were transported to the laboratory in the sampling tubes, which were stored at $9^{\circ} \mathrm{C}$ for up to one week, and then baited with $G$. mellonella. A single $G$. 
TABLE 2. Amplified fragment length polymorphism (AFLP) primers used to analyze populations of Steinernema feltiae.

\begin{tabular}{|c|c|c|}
\hline Adapter/primer & Abbreviation & Sequence \\
\hline$\overline{E c o \text { RI adapter } \dagger}$ & & $3^{\prime}$ CAT GTG ACG CAT GGT TAA 5' \\
\hline Tru 9I adapter (isoschizimer of $M s e I) \dagger$ & & $3^{\prime}$ TAC TCA GGA CTC AT $5^{\prime}$ \\
\hline Eco RI (Preselective primer) $\$$ & E01L & $5^{\prime}$ AGA CTG CGT ACC AAT TCA 3' \\
\hline Mse I (Preselective primer) $\$$ & M02 & $5^{\prime}$ GAT GAG TCC TGA GTA AC $3^{\prime}$ \\
\hline Eco RI + 2 primer $\$$ & E - AT NED & $5^{\prime}$ GAC TGC GTA CCA ATT CAA T 3' \\
\hline Eco RI + 2 primer $\$$, & E - AG JOE & $5^{\prime}$ GAC TGC GTA CCA ATT CAA G 3' \\
\hline$E c o$ RI +2 primers & E - TG FAM & $5^{\prime}$ GAC TGC GTA CCA ATT CAT G $3^{\prime}$ \\
\hline Mse I + 3 primer§ & $\mathrm{M}-\mathrm{CTG}$ & $5^{\prime}$ GAT GAG TCC TGA GTA ACC TG 3' \\
\hline Mse I +3 primer & $\mathrm{M}-\mathrm{AAT}$ & 5' GAT GAG TCC TGA GTA ACA AT 3' \\
\hline
\end{tabular}

Note: Preselective and selective amplification primers were previously used for analysis of close relatives of $S$. feltiae as determined from the nematode phylogeny of Blaxter et al. (1998).

$\dagger$ Standard AFLP adapters supplied by Applied Biosystems, Birchwood, Warrington, Cheshire, UK.

$\$$ Primers previously used in Otsen et al. (2001).

$\S$ Primers previously used in Tzortzakakis et al. (1999)

$\uparrow$ Primers previously used in Dautova et al. (2002)

mellonella larva was placed on top of each core, and the tube inverted. Nematode-induced mortality, based on the color and consistency of the cadaver, was recorded after seven days. Samples that were initially negative for nematodes were rebaited for a further seven days using fresh G. mellonella. Nematodes were identified to species level (48 and 60 months only), based on morphology. Morphological characteristics used for diagnosis of Steinernema species were obtained from first generation males and infective juveniles (Adams and Nguyen 2002). The genetic relatedness of the applied strains and the nematodes recovered on site 148 months after application was investigated using AFLP.

\section{AFLP}

For each bait cadaver, infective juveniles were harvested daily for three days from the time of first emergence. DNA was extracted from the pooled group of infective juveniles emerging from a single cadaver using a DNeasy kit (Qiagen, Valencia, California, USA). The nematodes emerging from each cadaver were therefore considered a separate population. As there are no published AFLP primers for EPN, the nematode phylogeny of Blaxter et al. (1998) was studied for close relatives of Steinernema. The closest phylogenetically related nematodes to Steinernema with published AFLP primers were Meloidogyne spp. Primers used for analysis and their sources are shown in Table 2. Isolated DNA was amplified using three different AFLP primer combinations based on the protocol of Vos et al. (1995). Genomic DNA was digested with Tru 91 (an isoschizimer of $M s e \mathrm{I}$ ) and EcoRI restriction enzymes and ligated with the provided adaptors (AFLP ligation and preselective amplification module; Applied Biosystems, Birchwood, Warrington, Cheshire, UK). The subset of restriction fragments having one MseI and one EcoRI restriction end were then amplified in a preselective PCR cycle using a PTC-200 thermal cycler (Bio-Rad Laboratories, Waltham, Massachusetts, USA). The preselective amplification profile was an initial denature at $72^{\circ} \mathrm{C}$ for 2 minutes; 20 cycles of a further denature at $94^{\circ} \mathrm{C}$ for $20 \mathrm{~s}$, annealing at $56^{\circ} \mathrm{C}$ for $30 \mathrm{~s}$ and extension at $72^{\circ} \mathrm{C}$ for 2 minutes; a final extension at $60^{\circ} \mathrm{C}$ for $30 \mathrm{~s}$. This was followed by a selective PCR cycle, which amplified a narrower subset of fragments using three different primer pairs. EcoRI selective primers were labeled with the fluorescent labels 6-Fam (blue), Joe (green), and Ned (yellow; Applied Biosystems). The selective amplification profile was an initial denature at $94^{\circ} \mathrm{C}$ for 2 minutes; 10 cycles of further denature at $94^{\circ} \mathrm{C}$ for $20 \mathrm{~s}$, annealing at $66-57^{\circ} \mathrm{C}$ for $30 \mathrm{~s}$ and extension at $72^{\circ} \mathrm{C}$ for 2 minutes; 20 cycles of further denature at $94^{\circ} \mathrm{C}$ for $20 \mathrm{~s}$, annealing at $56^{\circ} \mathrm{C}$ for $30 \mathrm{~s}$ and extension at $72^{\circ} \mathrm{C}$ for 2 minutes, and final extension at $60^{\circ} \mathrm{C}$ for $30 \mathrm{~s}$.

Following digestion, preamplification, and selective amplification, labeled PCR product was analyzed using an Applied Biosystems ABI 310 Genetic Analyser using GENESCAN and fragment length data was converted into a binary matrix using GENOTYPER (Applied Biosystems). This matrix was then uploaded to Genalex 6 (Peakall and Smouse 2006). Pairwise genetic distances between individual samples was calculated according to the method of Huff et al. (1993), and principal coordinates analysis (PCO) of pairwise genetic distance data was carried out using a multivariate algorithm (Orloci 1978).

\section{Statistical analysis}

Routine statistics were performed using MINITAB Release 14 for Windows (Minitab Inc. 2000). Significance levels were taken at $P<0.05$. Data were tested for normality using the Anderson Darling test and, where found to be non-normal, data were transformed. More than two treatments were compared using general linear model ANOVA, followed by pairwise comparisons (Tukey test; alpha $=0.05$ ). Analysis was performed on average site values, rather than mean number of positive cores per stump, due to the large number of zeros for individual stump data. Total number of cores positive for $S$. feltiae after 48 and 60 months were compared using chi-square analysis. 
TABLE 3. Number of bait insects (Galleria mellonella [mean \pm SE]) killed by Steinernema carpocapsae, Steinernema feltiae, and Heterorhabditis downesi per mesocosm 9, 14, and 19 weeks after application of 0.5 million infective juveniles to pine forest mesocosms.

\begin{tabular}{|c|c|c|c|c|}
\hline \multirow[b]{2}{*}{ Nematode species } & \multicolumn{4}{|c|}{ No. weeks after nematode application } \\
\hline & 9 & 14 & 19 & Overall \\
\hline$\overline{\text { S. carpocapsae }}$ & $66 \pm 1$ & $56 \pm 14$ & $23 \pm 11$ & $46^{\mathrm{b}} \pm 10$ \\
\hline S. feltiae 4CFMO & $142 \pm 2$ & $175 \pm 14$ & $202 \pm 1$ & $177^{\mathrm{a}} \pm 14$ \\
\hline H. downesi & $76 \pm 4$ & $53 \pm 12$ & $41 \pm 2$ & $54^{\mathrm{b}} \pm 7$ \\
\hline
\end{tabular}

Note: Different superscript letters in the final column denote differences between the overall numbers of $G$. mellonella killed by entomopathogenic nematodes (EPN; ANOVA, Tukey test $P<$ $0.05)$.

\section{RESUlTS}

\section{Persistence and dispersal of entomopathogenic} nematodes in mesocosms

No caged $H$. abietis were killed by EPN at any of the three sampling dates. Over the duration of the experiment, average weekly soil temperature in the boxes ranged from $8-11.5^{\circ}, 11-15.5^{\circ}$, and $15.5-22^{\circ} \mathrm{C}$ during weeks $0-9,9-14$, and $14-19$, respectively.

The number of bait $G$. mellonella per mesocosm killed by nematodes was influenced by nematode species $\left(F_{2,15}\right.$ $=21.02, P<0.001)$; sampling time had no effect and there was no interaction between the two factors $\left(F_{2,15}=\right.$ $2.70, P>0.05$ and $F_{4,15}=2.122, P>0.05$, respectively). Significantly more $G$. mellonella were killed by $S$. feltiae than by either of the other two species $(P<0.05$; Table 3).

EPN (as measured by dead bait insects) were rather uniformly distributed vertically throughout the peat columns (Fig. 1). Each of the three nematode species dispersed laterally from the zone of application (0-5 $\mathrm{cm})$, but dispersal was limited. Few EPN were recovered 16-20 $\mathrm{cm}$ from the zone of application (maximum sampling distance) when boxes were sampled 9 or 14 weeks after nematode application (Fig. 1A, B). Higher numbers of dead bait insects were recovered at that distance at the 19-week sampling (Fig. 1C).

\section{Persistence of entomopathogenic nematodes in the field}

Persistence of EPN was studied at sites 1 and 2 for five and four years after application, respectively. EPN were recovered from the vicinity of stumps treated with each of the applied nematode treatments $(S$. carpocapsae, $S$. feltiae 4CFMO, S. feltiae EN02, $H$. megidis, and $H$. downesi) up to three years after application. Although not identified to species, the nematodes recovered from each nematode-treated stump corresponded to the genus that had been applied to that stump (based on cadaver color and consistency). One month after application, EPN were recovered from $99 \%$ of the stumps to which they had been applied (Fig. 2). The time elapsed since nematode application significantly affected the percentage of treated stumps positive for EPN $\left(F_{3,20}=18.52, P\right.$ $<0.001)$, but nematode species $\operatorname{did} \operatorname{not}\left(F_{4,20}=1.06, P>\right.$ 0.05 ) and there was no interaction between the two factors $\left(F_{12,20}=0.42, P>0.05\right)$. The percentage of stumps with EPN remained high for two years, but significantly lower values were recorded in the 36-38 month samples $(36 \%)$ than in the 1,12 , and 24 month samples $(88-99 \%$; $P<0.05$; Fig. 2). The percentage of stumps from which nematodes were recovered ranged from $70 \%$ for $H$. downesi to $86 \%$ for S. feltiae 4CFMO, averaged over all sampling times.

When analysis was done on cores, both nematode species and time since application had a significant effect on the proportion of cores positive for EPN $\left(F_{4,20}=\right.$ 3.50, $P<0.05$ and $F_{3,20}=16.80, P<0.001$, respectively), with no interaction between the two factors $\left(F_{12,20}=0.90, P>0.05\right)$. Steinernema feltiae 4CFMO was recovered from the highest percentage of cores and $H$. downesi from the lowest $(35.5 \% \pm 5.4 \%$ and $19.7 \% \pm 5.2 \%$, respectively; Tukey test $P<0.05$ ) (Fig. 3A). As for stumps, fewer cores had EPN at the 36-38 month sampling $(9.1 \%)$ than in the 1,12 , and 24 month samples (25.6-38.5\%, $P<0.05$; Fig. 3B).

Site 1 was sampled 48 and 60 months after nematode application, and EPN were recovered from $1.2 \%$ and $0.9 \%$ of soil cores, respectively $\left(\chi^{2}=0.48,1 \mathrm{df}, P>\right.$ $0.05)$. Positive cores were recorded from stumps treated with $S$. carpocapsae, S. feltiae 4CFMO, H. megidis, and $H$. downesi (Table 4), but all recovered EPN were identified as $S$. feltiae based on morphology. When site 2 was sampled 48 months after nematode application, $S$. feltiae was recovered from stumps to which both strains (EN02 and 4CFMO) of that species, and also $S$. carpocapsae had been applied; again, no other nematode species was detected. The prevalence (percentage of soil cores) of $S$. feltiae 48 months after nematode application was similar on sites 1 and $2(1.2 \%$ and $2.1 \%$ of soil cores, respectively; $\chi^{2}=2.208,1 \mathrm{df}, P>0.05$; Table 4$)$.

\section{Dispersal of entomopathogenic nematodes in the field}

Dispersal at the stump.-The distribution of EPN around stumps treated with $S$. carpocapsae, $H$. downesi, and S. feltiae 4CFMO was investigated in detail on all three sites at 1 and 12 months after nematode application (Fig. 4). Distance from zone of application $(0$ and $20 \mathrm{~cm})$ had a highly significant effect on EPN recovery $\left(F_{1,48}=\right.$ 104.44, $P<0.001$; Fig 4$)$, with three to four times as many cores positive where EPN were applied $(0 \mathrm{~cm})$ compared to at $20 \mathrm{~cm}$ out from the zone of application. Neither the depth at which the core was taken $(0-5$ and 


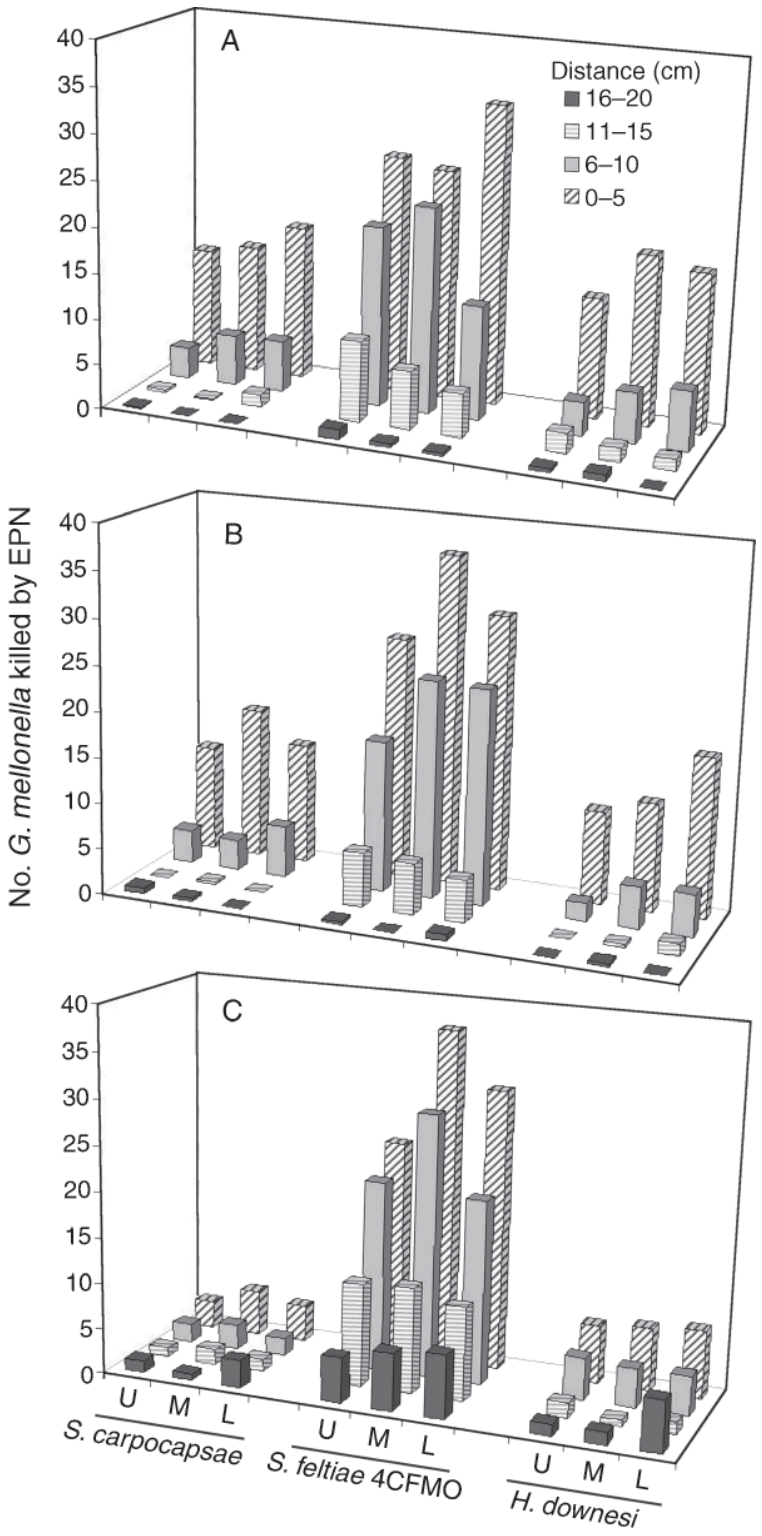

FIG. 1. Distribution in pine forest mesocosms of each of the three nematode species (Steinernema carpocapsae, Steinernema feltiae, and Heterorhabditis downesi) (A) 9, (B) 14, and (C) 19 weeks following application of 0.5 million infective juveniles, as indicated by baiting with Galleria mellonella. Upper (U), middle (M), and lower (L) refer to layers of peat (each $\sim 5 \mathrm{~cm}$ in depth) Distance $0-5,6-10,11-15$, and 16-20 refer to the horizontal distance $(\mathrm{cm})$ from the zone of application (around log). EPN stands for entomopathogenic nematodes.

6-10 cm; $\left.F_{1,48}=0.00, P>0.05\right)$ nor sampling time $\left(F_{1,48}\right.$ $=1.53, P>0.05)$ had an effect. Nematode species was significant $\left(F_{2,48}=3.75, P<0.05\right)$, with EPN recovered from the same proportion of cores at $S$. carpocapsae and $S$. feltiae treated stumps, but from more $S$. carpocapsae than $H$. downesi treatments $(P<0.05)$. There were no interactions between any of the factors (distance, depth, time, or nematode species; $P>0.05$ ).
Spread to untreated control stumps.-Nematodes were recovered from cores taken at control (water-treated) stumps starting from 1, 12, and 24 months after nematode application on sites 3, 2, and 1 respectively (Table 5). All of the EPN recovered from control stumps were identified as Steinernema spp based on color and consistency of the infected $G$. mellonella cadavers. Although the highest percentage of positive cores was less than $14 \%$ (24 months after application on site 1), EPN were recovered from 53\% (10/19) of stumps at that time, indicating a widespread distribution within the experimental area. This was a transient effect, as the percentage of control stumps with EPN ranged from $0 \%$ to $10.5 \%$ over the next three years.

Spread away from stumps, and to stumps outside treated area.-To investigate whether EPN were distributed randomly throughout the test site, or concentrated around the stumps, non-stump samples were taken 12 , 48, and 60 months after nematode application on sites 3 , 2 , and 1, respectively. EPN were not recovered from any of the 600 non-stump cores taken within the experimental area (two cores at each of 100 locations at each site). Similarly, EPN were not detected in any of the 114 stump cores (19 upper and lower cores at 1, 5, and $10 \mathrm{~m}$ from the edge of site 1) taken to assess dispersal to stumps outside the treated area $1,12,24$, or 36 months after application.

\section{Relatedness of entomopathogenic nematodes recovered 48 months after application to site 1 , as measured using AFLP analysis}

We measured the genetic relatedness of the $11 \mathrm{~S}$. feltiae populations recovered on site 148 months after nematode application and the two strains of $S$. feltiae (4CFMO and EN02) that had been initially applied to the site.

In total, 275 polymorphic bands were generated for the 13 populations by the three AFLP primer pairs, of which 131 were informative (shared by at least two

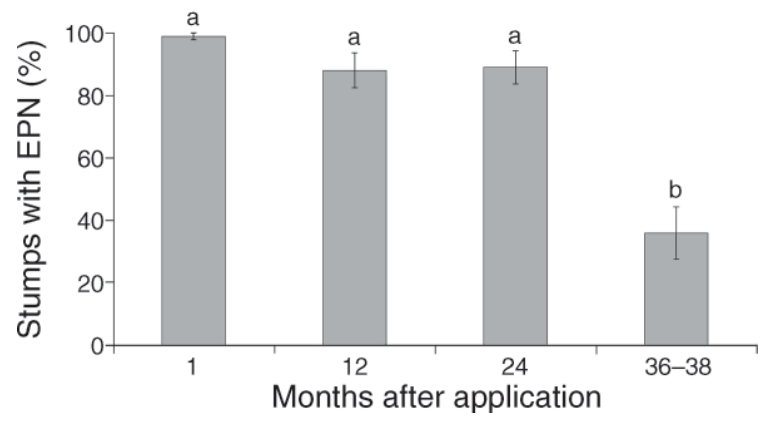

FIG. 2. Percentage (mean \pm SE) of stumps with entomopathogenic nematodes (EPN) recovered from nematode-treated stumps 1, 12, 24, and 36-38 months after application of 3.5 million infective juveniles/stump (mean of sites 1 and 2). Different letters above columns indicate significant differences between treatments (Tukey test at $P=0.05$, following ANOVA $P<0.05)$. The total number of stumps per sampling period $=$ 95 (site 1) or 50 (site 2). 


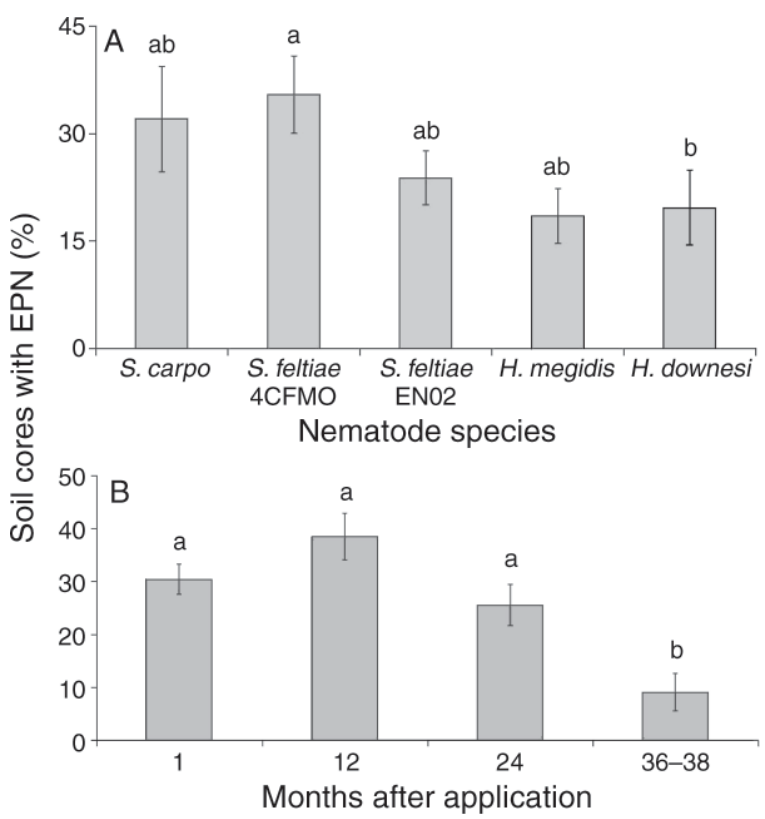

FIG. 3. Percentage (mean \pm SE) of soil cores with entomopathogenic nematodes recovered from nematode-treated stumps following application of 3.5 million infective juveniles/stump (mean of sites 1 and 2). (A) Recovery by nematode species $(S$. carpo $=$ Steinernema carpocapsae $)$. The number of soil cores per nematode treatment $=760$ (site 1) or 400 (site 2). (B) Recovery by sampling period. The number of soil cores per sampling period $=1520(1 \mathrm{month})$ or 760 (all other sampling periods) on site 1 and 800 (1 month) or 400 (all other sampling periods) on site 2 . Different letters above a column indicate significant differences between treatments (Tukey test at $P=0.05$, following ANOVA $P<0.05$ ).

populations). Two principal summary axes of pairwise genetic distance data generated in principal coordinates analysis (PCO) were used to generate a two-dimensional scatter plot of genetic relatedness between populations (Fig. 5). The principal summary axis explained $33.4 \%$ of variation in the data set, while the cumulative variation explained by including the second and third axes was $54.7 \%$ and $70.2 \%$, respectively. It is clear from Fig. 5 that all of the $S$. feltiae populations recovered from the trial site have a much closer genetic affinity to the applied Irish S. feltiae 4CFMO (population 13) than to the applied exotic $S$. feltiae EN02 (population 12). One distinct cluster was observed (populations 1-5). The group encompassing populations 1-5 inclusive is most closely related to the applied Irish $S$. feltiae (population 13) on both PCO axes. Four of these populations (1-4) were recovered from stumps to which the indigenous $S$. feltiae 4CFMO had been applied, while the fifth population was recovered from a $S$. carpocapsae-treated stump. The remaining $S$. feltiae populations were recovered from stumps that had been treated with $S$. carpocapsae (populations 6-8), H. downesi (populations 9 and 10), or H. megidis (population 11).

One of the H. downesi-treated stumps (HD B9), one of the indigenous $S$. feltiae-treated stumps (SF 4CFMO B7), and one of the $S$. carpocapsae-treated stumps (SC B2) each yielded two $S$. feltiae infected cadavers: populations 9 and 10, 2 and 4, and 5 and 6, respectively. In two of these cases, populations from the same stump did not form distinct groups (populations 9 with 10 or 5 with 6 , respectively), indicating that two genetically different populations were present at each of these stumps. The two populations recovered from the indigenous S. feltiae-treated stump SF 4CFMO B7 (strains 2 and 4) clustered closely together.

\section{Discussion}

Biological control of a number of economically important forest insect pests has been achieved through the establishment of applied natural enemies in forest ecosystems. Examples include the nematode Deladenus siricidicola Bedding against the wood wasp Sirex noctilio F., nucleopolyhedroviruses against European sawfly species, Gilpinia hercyniae Hartig and Neodiprion sertifer Geoffrey, and the parasitoid Pauesia sp. against the black pine aphid, Cinara cronartii Tissot and Pepper (Kidd and Jervis 1997, Hajek et al. 2007). The higher success rate of introductions against pests of perennial crops (forestry and orchards), compared to pests of annual crops has mainly been attributed to the occurrence of pest and natural enemies together in time and space in the former (Symondson et al. 2002, Hajek et al. 2007). As part of this study, we investigated the

TABLE 4. Prevalence of Steinernema feltiae around stumps to which four species of entomopathogenic nematodes (EPN) had been applied 48 and 60 months previously.

\begin{tabular}{|c|c|c|c|c|c|c|}
\hline \multirow{4}{*}{$\begin{array}{c}\text { Nematode } \\
\text { species applied }\end{array}$} & \multicolumn{6}{|c|}{ Stumps (or cores) with EPN (\%) } \\
\hline & \multicolumn{4}{|c|}{ Site 1} & \multirow{2}{*}{\multicolumn{2}{|c|}{$\begin{array}{c}\text { Site } 2 \\
\text { After } 48 \text { months }\end{array}$}} \\
\hline & \multicolumn{2}{|c|}{ After 48 months } & \multicolumn{2}{|c|}{ After 60 months } & & \\
\hline & Stumps & Cores & Stumps & Cores & Stumps & Cores \\
\hline S. carpocapsae & 15.9 & 2.6 & 10.6 & 1.3 & 20 & 2.5 \\
\hline S. feltiae 4CFMO & 15.9 & 2.6 & 5.3 & 1.3 & 20 & 2.5 \\
\hline S. feltiae EN02 & 0 & 0 & 0 & 0 & 30 & 8.8 \\
\hline$H$. megidis & 5.3 & 0.7 & 5.3 & 0.7 & 0 & 0 \\
\hline H. downesi & 5.3 & 1.3 & 5.3 & 0.7 & 0 & 0 \\
\hline
\end{tabular}
2).

Notes: Number of stumps $=19$ (site 1$)$ or 10 (site 2$)$. Number of soil cores $=152$ (site 1$)$ or 80 (site 


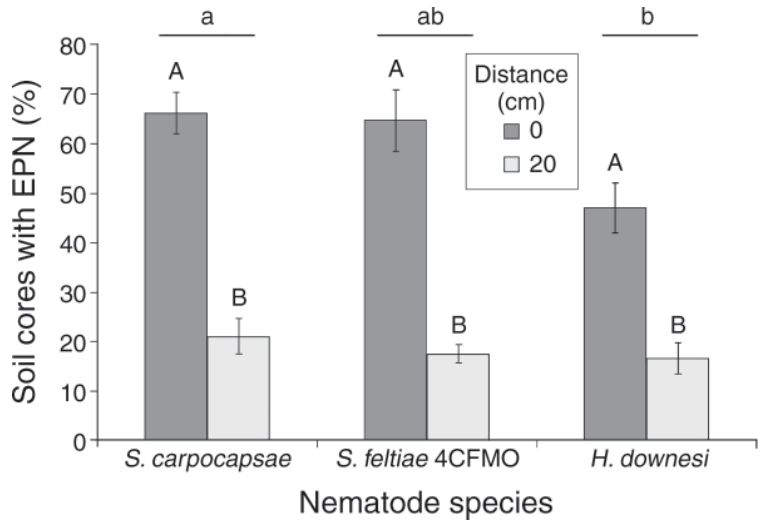

FIG. 4. Percentage (mean $\pm \mathrm{SE}$ ) of soil cores from different locations around stumps positive for entomopathogenic nematodes after application of 3.5 million infective juveniles/stump Values at 1 and 12 months were pooled to generate the graph. Distance $=$ distance from stump at which nematodes were applied. Different uppercase letters above columns indicate a significant difference between distance treatments, and different lowercase letters above a pair of columns indicate significant differences between nematode species (Tukey test at $P=0.05$, following ANOVA $P<0.05)$. Means are of three sites. The number of soil cores at each location $=228$ (site 1$)$ and 120 (sites 2 and 3 ).

persistence of four species of EPN ( $S$. feltiae, $S$. carpocapsae, $H$. megidis, and $H$. downesi) following their inundative application to pine stumps containing immature $H$. abietis. Stumps only remain suitable for H. abietis development for the first few years after felling, and the next available source of hosts in a felling coup may be located at some distance. Coexistence between the pest and applied EPN in the long-term is unlikely based on limited dispersal of the nematodes. It was therefore our hypothesis that all of the applied nematode species might persist as long as stumps harbor immature $H$. abietis, but based on background knowledge of biogeography, habitat preferences, and host range only S. feltiae would persist subsequently.

As predicted, the exotic species $S$. carpocapsae and $H$. megidis failed to establish in the peaty forest soils in the field studies. This prediction was based primarily on the rarity of the former species in Northern Europe and the close association of the latter with sandy soils (Griffin et al. 1999, Hominick 2002). The indigenous species $H$. downesi also failed to establish, a result that was also predicted based on the association of this species with sandy soils (Griffin et al. 1999). Of all the EPN species tested, $S$. feltiae was considered the most likely to establish and persist in this environment, based on the fact that this species naturally occurs in Irish coniferous forest soils (Dillon 2003) and supported by its higher recovery and excellent persistence in the mesocosms. In the field studies, EPN were recovered from stumps treated with all species for up to three years, but $S$. feltiae was the only nematode species recovered after 48 and 60 months. Persistence of EPN for more than one year following inundative application is not unexpected (Ferguson et al. 1995, Shields et al. 1999, Millar and Barbercheck 2001). Longer term studies are rare, but Steinernema scapterisci Nguyen and Smart was recovered from pasture sites in Florida for up to five years following its introduction for use against mole crickets (Orthoptera: Gryllotalpidae; Parkman et al. 1996). The findings presented in this paper demonstrate the importance of medium-term studies, as conclusions based on only 36 months of sampling would have overestimated the risk of establishment of three of the four nematode species tested.

The pine forest mesocosm experiment showed that all three species tested (S. carpocapsae, S. feltiae, and $H$. downesi) could persist in peat soil for at least four months, and that $S$. feltiae persisted at the highest rate (as measured by number of dead bait insects). This study assessed the survival of the applied nematodes, in the absence of reproduction and the release into the soil of subsequent generations. It is likely that persistence of EPN populations over a number of years depends on the availability of hosts through which the EPN can recycle, as well as the survival ability of the infective juveniles. All of the species tested recycled in H. abietis in the field (Dillon 2003). The percentage of stumps from which nematodes were recovered dropped significantly by $36-$ 38 months; by which time the number of wood associated beetles (including $H$. abietis) would be greatly

TABLE 5. Spread of entomopathogenic nematodes to water-treated control stumps on three sites following inundative application of nematodes to pine stumps.

\begin{tabular}{|c|c|c|c|c|c|c|}
\hline \multirow{3}{*}{$\begin{array}{l}\text { Months after } \\
\text { EPN application }\end{array}$} & \multicolumn{6}{|c|}{ Control stumps and cores with EPN (\%) } \\
\hline & \multicolumn{2}{|c|}{ Site 1} & \multicolumn{2}{|c|}{ Site 2} & \multicolumn{2}{|c|}{ Site 3} \\
\hline & Stumps & Cores & Stumps & Cores & Stumps & Cores \\
\hline 1 & 0 & 0 & 0 & 0 & 20 & 1.9 \\
\hline 12 & 0 & 0 & 10 & 2.5 & 30 & 5 \\
\hline 24 & 53 & 13.8 & 0 & 0 & & \\
\hline 36 & 5.26 & 0.7 & 20 & 8.8 & & \\
\hline 48 & 0 & 0 & 10 & 1.3 & & \\
\hline 60 & 10.5 & 1.3 & & & & \\
\hline
\end{tabular}

Notes: Number of stumps per site $=19$ (site 1) or 10 (sites 2 and 3). Number of soil cores $=304$ (site 1 at 1 month), 152 (site 1 at all subsequent sampling periods), 160 (sites 2 and 3 at 1 month), or 80 (sites 2 and 3 at all subsequent sampling periods). Empty cells indicate that no sample was taken. 


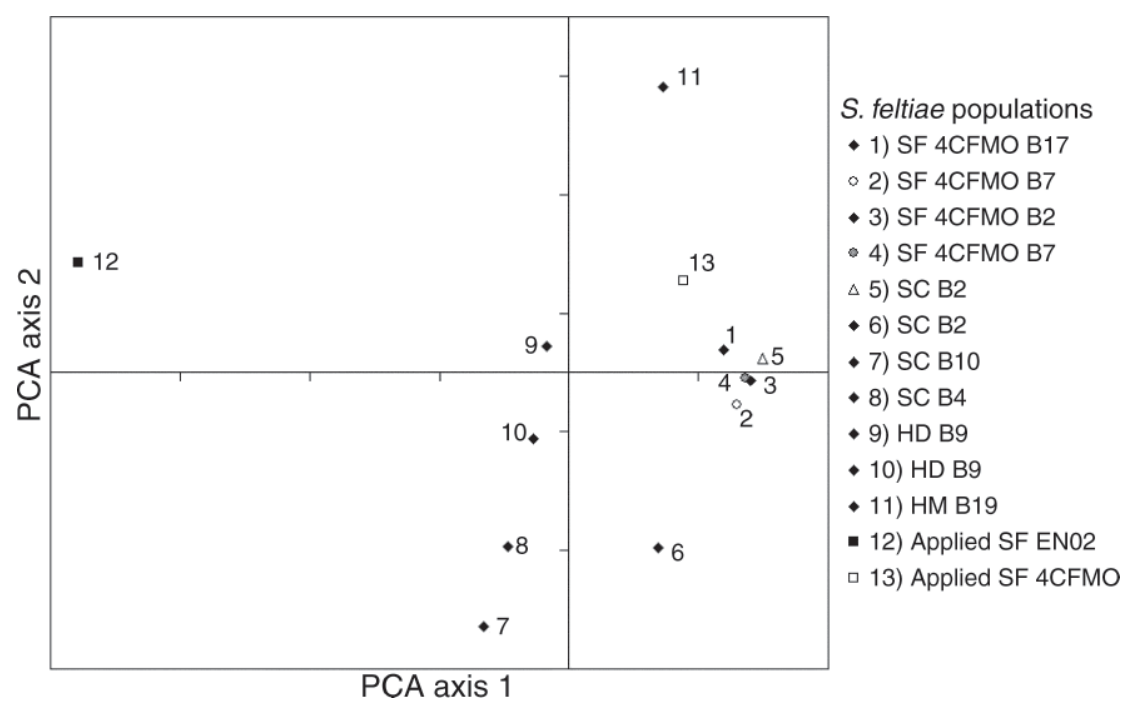

FIG 5. Principal coordinates analysis of genetic relatedness between 13 S. feltiae populations based on pairwise genetic distance data produced using amplified fragment length polymorphism (AFLP) molecular markers. The 13 populations included 11 populations recovered 48 months after inundative application of entomopathogenic nematodes to a clearcut pine site in 2001 (1-11) and the two strains that were initially applied to the site: Steinernema feltiae EN02 (12) and S. feltiae 4CFMO (13). Recovered population names refer to the stump treatment and the block from which they were recovered. For example HD B9 was isolated from a stump in block 9 treated with Heterorhabditis downesi. $\mathrm{HD}=$ Heterorhabditis downesi, $\mathrm{HM}=$ Heterorhabditis megidis, $\mathrm{SC}=$ Steinernema carpocapsae, SF 4CFMO = Irish strain of S. feltiae, and SF EN02 = exotic strain of S. feltiae.

reduced due to excessive degradation of the stump (Wallace 1954, Wainhouse et al. 2001). Once H. abietis are absent (approximately five years after felling), EPN must propagate in alternative host insects in order to successfully establish in a pine forest ecosystem. Laboratory studies have shown that EPN species can infect a wide range of insect species $(>200$ species from several orders; Poinar 1986, Peters 1996), though the wide potential host range observed in such studies almost certainly overestimates that of field conditions (Ehlers and Peters 1995, Bathon 1996). Information about natural host range is limited because most hosts occur within the soil, and infected insects disintegrate after the infective juveniles emerge from the cadavers. As the stump fauna changed over time the reduction in numbers of suitable hosts may have contributed to the disappearance of $H$. megidis, $H$. downesi, and S. carpocapsae by month 48 . Heterorhabditis megidis appears to be a coleopteran specialist (Peters 1996) and its disappearance may be linked to the replacement of beetle dominated fauna by Diptera and Hymenoptera. Steinernema feltiae and $S$. carpocapsae both exhibit broad host ranges (Peters 1996), so lack of suitable hosts is unlikely to have accounted for the failure of the latter to establish. The rarity of $S$. carpocapsae in northern Europe (Sturhan 1999, Hominick 2002) is not explained, but may indicate that factors additional to host availability prevented the establishment of this nematode. Steinernema feltiae naturally occurs in clearcut coniferous forests in Ireland (Griffin et al. 1991, Dillon 2003) indicating that this species propagates through insects found in this habitat.
Although this study did not attempt to investigate nontarget effects of EPN applied in a forest ecosystem, the failure to recover either $H$. downesi or the exotic species of EPN ( $S$. carpocapsae and H. megidis) and the extremely low prevalence of $S$. feltiae 48 and 60 months after application (approximately 1-2\% of cores) would suggest that even if the applied EPN propagated in insects other that $H$. abietis, nontarget effects on insect populations must be considered minimal and/or transient. Any changes in nontarget insect populations that have been observed following the application of EPN have been short lived and spatially restricted, so that even where a nontarget effect is observed, its impact on the overall population is of minor significance (Bathon 1996). While nontarget effects of EPN on soil nematode communities and soil processes have been reported (Somasekhar et al. 2002a, De Nardo et al. 2006), certain reported nontarget effects could be considered beneficial (e.g., reduction in abundance of plant parasitic nematodes).

The nematode distribution in the pine forest mesocosms and in the vicinity of the stumps demonstrates that although $S$. feltiae, $S$. carpocapsae and $H$. downesi are capable of dispersing up to $20 \mathrm{~cm}$ from the zone of application, the majority of nematodes (as measured by the number of nematode infected bait insects) remain close to the point at which they were applied, as is typical for EPN (e.g., Csontos 2002). The absence of EPN from non-stump cores indicates that active dispersal of EPN in detectable numbers is limited to $<1 \mathrm{~m}$. However, the recovery of $S$. feltiae from control stumps and stumps treated with EPN other than $S$. 
feltiae suggests either colonization by rare dispersers or that this nematode was carried phoretically. Phoretic dispersal of EPN can occur either in hosts that survive long enough after infection to allow the infective juveniles to emerge somewhere other than the site of initial infection (Downes and Griffin 1996), or through the use of non-host organisms such as ants that act as facultative dispersal agents (Baur et al. 1998). Parkman et al. (1993) reported that infected mole crickets disperse $S$. scapterisci to create new foci for infection, and it is possible that adult $H$. abietis also facilitate the dispersal of EPN, as they visit stumps for egg laying. Adult weevils can survive for up to 12 days after infection (D. Ennis, unpublished data), so a weevil might become infected at one stump and die close to another, releasing thousands of infective juveniles that developed inside the insect. A species failing to persist locally may persist regionally due to a balance between local extinction and recolonization (Hanski 1991). As migration is required for recolonization, and recolonization is required for metapopulation persistence in the face of unstable local dynamics, long-term establishment of populations of $H$. downesi, H. megidis, or S. carpocapsae within the forest ecosystem seems unlikely, based on their limited dispersal within the experimental area and their absence from samples taken at stumps outside the treated area.

As no EPN were recovered on any of the three sites prior to the inundative application, possible displacement of indigenous species could not be investigated. In a more EPN diverse ecosystem it is possible that applied EPN could compete with native populations for insect hosts, ultimately resulting in displacement of indigenous EPN. Complete displacement of native EPN populations was not observed following application of Steinernema riobrave Cabanillas, Poinar and Raulston to corn plots (Millar and Barbercheck 2001) and is unlikely based on the fact that more than one species of EPN naturally coexist in the field even when exploiting the same host (Bovien 1937). In this paper, we used AFLP to test for hybridization between the two applied strains of S. feltiae (exotic and indigenous to Ireland). Based on the AFLP results, it is clear that all of the $S$. feltiae populations recovered from the experimental area have a much closer genetic affinity to the applied Irish $S$. feltiae strain (4CFMO) than to the applied exotic $S$. feltiae strain (EN02). As there is some variance between the recovered $S$. feltiae populations and the applied Irish $S$. feltiae strain it is not possible to say definitively that the recovered and applied populations are one and the same, though there is a clear pattern in the data pointing to the persistence of the applied Irish genotype at the trial site. That some populations are clustered close to one another (e.g., populations 1-5) and others are more dispersed suggests a number of possible population genetic scenarios. Clustering may be an artifact of a genetic bottleneck that resulted from a founder effect, or genetically dispersed populations may be reflecting survival of individual lineages, each founded by a genetically distinct colonist. The latter theory is supported by the fact that $S$. feltiae populations recovered from stumps treated with nematodes other than $S$. feltiae generally showed greater genetic difference from the applied $S$. feltiae strains. Equally, it may be that interbreeding has diffused the genetic identity of some strains through crossing with indigenous populations, though this is unlikely since none of the latter were recovered in pre-trial baiting of the site. Genetic drift might also explain the emergence of disparate identities among the recovered populations, although it is unclear whether the timeframe from application to resampling (four years) and the limited spatial distribution (20000 $\mathrm{m}^{2}$ ) of the sampled populations would be sufficient for drift to occur without any hybridization occurring. That the indigenous $S$. feltiae strain (4CFMO) would establish rather than the exotic strain of this species (EN02) was not unexpected, as the indigenous strain was recovered from a similar habitat (peat soil in a clearcut coniferous forest), and so was possibly preadapted to such conditions. The exotic S. feltiae (strain EN02) is a commercially produced nematode, and presumably EPN that are produced in bioreactors are selected for their fermenter competence and rapid knockdown of target insects, rather than for long-term persistence in the field. Establishment of the applied indigenous $S$. feltiae strain beyond availability of pine weevil was probably facilitated through its propagation through alternative hosts that this species normally encounters under natural conditions. We cannot discount the possibility that in certain situations an exotic strain may exploit alternative hosts and establish, but based on the genetic dissimilarities between the applied exotic and recovered isolates, this does not seem to have occurred in this instance.

\section{CONCLUSIONS}

Although all species persisted over a number of seasons, only $S$. feltiae established. The mesocosm provided a useful indicator of the likelihood of nematode persistence, where the recovery rate of $H$. downesi and $S$. carpocapsae was less than for $S$. feltiae. The limited horizontal displacement and uniform vertical distribution observed in the mesocosm was reiterated in the field studies. The failure to recover EPN outside the treated area, the dramatic drop in nematode recovery 48 and 60 months after their application, and the fact that no species or strains exotic to the forest ecosystem were recovered at the final sampling dates confirms that the risk of dispersal and establishment associated with the inundative application of the exotic species $H$. megidis and $S$. carpocapsae against the large pine weevil in Ireland must be considered relatively minor. We conclude that information on environmental suitability and ecological host range should be made available to pest managers in order to predict the likelihood of establishment of exotic entomopathogenic 
nematodes where they are used in inundative biological control programs.

\section{ACKNOWLEDGMENTS}

Nematodes were applied under license (TA003/01) from the Pesticide Control Services of the Irish Department of Agriculture and Food. Research was funded by the National Council for Forest Research and Development (COFORD) through the Irish National Development Plan 2001-2006 and by the European Union INTERREG IIIA administered through the Welsh European Funding Office on behalf of the Welsh Assembly Government. Coillte Teoranta provided field sites and technical support. We thank the staff and summer students of the Biology Department, NUIM, for their assistance with sampling. The authors are grateful to $\mathrm{E}$ nema $\mathrm{GmbH}$ (Germany), Koppert Biological Systems (UK and Holland), and Becker Underwood Inc (UK) for supplying nematodes.

\section{Literature Cited}

Adams, B. J., and K. B. Nguyen. 2002. Taxonomy and systematics. Pages 1-33 in R. Gaugler, editor. Entomopathogenic nematology. CABI Publishing, New Jersey, USA.

Bakke, A., and B. Lekander. 1965. Studies on Hylobius abietis L. 2. Meddelelse fra det Norske Skogforsoksvesen 20:117135.

Bathon, H. 1996. Impact of entomopathogenic nematodes on non-target hosts. Biocontrol Science and Technology 6:421434

Baur, M. E., H. K. Kaya, and D. R. Strong. 1998. Foraging ants as scavengers on entomopathogenic nematode-killed insects. Biological Control 12:231-236.

Bedding, R. A., and R. J. Akhurst. 1975. A simple technique for the detection of insect parasitic rhabditid nematodes in soil. Nematologica 21:109-110.

Blackshaw, R. P. 1988. A survey of insect parasitic nematodes in Northern Ireland. Annals of Applied Biology 113:561-565.

Blaxter, M. L., P. De Ley, J. R. Garey, L. X. Liu, P. Scheldeman, A. Vierstraete, J. R. Vanfleteren, L. Y. Mackey, M. Dorris, L. M. Frisse, J. T. Vida, and W. K. Thomas. 1998. A molecular evolutionary framework for the phylum Nematoda. Nature 6671:71-75.

Bovien, P. 1937. Some types of association between nematodes and insects. Videnskabelige Meddelelser fra Dansk Naturhistorisk Forening 101:1-144.

Brixey, J. M., R. Moore, and A. D. Milner. 2006. Effect of entomopathogenic nematode (Steinernema carpocapsae Weiser) application technique on the efficacy and distribution of infection of the large pine weevil (Hylobius abietis L.) in stumps of Sitka spruce (Picea sitchensis Carr.) created at different times. Forest Ecology and Management 226:161172.

Csontos, A. S. 2002. Lateral movement of the entomopathogenic nematodes Steinernema glaseri and Heterorhabditis bacteriophora in sand at different temperatures in response to host seeking. Biocontrol Science and Technology 12:137-139.

Dautova, M., H. Overmars, J. Bakker, G. Smart, and F. L. Gommers. 2002. Nuclear and mitochondrial DNA polymorphisms in three mitotic pathenogenetic Meloidogyne spp. European Journal of Plant Pathology 108:209-220.

DeBach, P., and D. Rosen. 1991. Biological control by natural enemies. Cambridge University Press, Cambridge, UK.

De Nardo, E. A. B., P. S. Grewal, D. McCartney, and B. R. Stinner. 2006. Non-target effects of entomopathogenic nematodes on soil microbial community and nutrient cycling processes: a microcosm study. Applied Soil Ecology 34:250 257.

Dillon, A. 2003. Biological control of the large pine weevil, Hylobius abietis L., (Coleoptera: Curculionidae) using entomopathogenic nematodes. Dissertation. National University of Ireland-Maynooth, Maynooth, Ireland.
Dillon, A. B., D. Ward, M. J. Downes, and C. T. Griffin. 2006. Suppression of the large pine weevil Hylobius abietis (Coleoptera: Curculionidae) in pine stumps by entomopathogenic nematodes with different foraging strategies. Biological Control 38:217-226.

Dillon, A. B., D. Ward, M. J. Downes, and C. T. Griffin. 2007. Optimizing application of entomopathogenic nematodes to manage large pine weevil, Hylobius abietis L. (Coleoptera: Curculionidae) populations developing in pine stumps, Pinus sylvestris. Biological Control 40:253-263.

Downes, M. J., and C. T. Griffin. 1996. Dispersal behaviour and transmission strategies of the entomopathogenic nematodes Heterorhabditis and Steinernema. Biocontrol Science and Technology 6:347-356.

Ehlers, R. U., and H. M. T. Hokkanen. 1996. Insect biocontrol with non-endemic entomopathogenic nematodes (Steinerne$m a$ and Heterorhabditis spp.): conclusions and recommendations of a combined OECD and COST Workshop on Scientific and Regulatory Policy Issues. Biocontrol Science and Technology 6:295-302.

Ehlers, R., and A. Peters. 1995. Entomopathogenic nematodes in biological control: feasibility, perspectives and possible risks. Pages 119-136 in H. M. T. Hokkanen and J. M. Lynch, editors. Biological control: benefits and risks. Cambridge University Press, Cambridge, UK.

Ellstrand, N. C., H. C. Prentice, and J. F. Hancock. 1999. Gene flow and introgression from domesticated plants into their wild relatives. Annual Review of Ecology and Systematics 30: 539-563.

Elton, E. T. G., H. F. H. Blankwaardt, H. C. Burger, W. F. Steemers, and L. G. Tichelman. 1964. Insect communities in barked and unbarked pine stumps, with special reference to the large pine weevil (Hylobius abietis L., Col., Curculionidae). Journal of Applied Entomology 55:1-54.

Ferguson, C. S., P. C. Schroeder, and E. J. Shields. 1995. Vertical-distribution, persistence and activity of entomopathogenic nematodes (Nematoda, Heterorhabditidae and Steinernematidae) in alfalfa snout beetle (Coleoptera, Curculionidae) infested fields. Environmental Entomology 24: $149-158$.

Forst, S., B. Dowds, N. Boemare, and E. Stackebrandt. 1997. Xenorhabdus and Photorhabdus spp.: bugs that kill bugs. Annual Review of Microbiology 51:47-72.

Georgis, R., A. M. Koppenhofer, L. A. Lacey, G. Belair, L. W. Duncan, P. S. Grewal, M. Samish, L. Tan, P. Torr, and R. W. H. M. van Tol. 2006. Successes and failures in the use of parasitic nematodes for pest control. Biological Control $38: 103-123$

Griffin, C. T., I. Dix, S. A. Joyce, A. M. Burnell, and M. J. Downes. 1999. Isolation and characterisation of Heterorhabditis spp. (Nematoda: Heterorhabditidae) from Hungary, Estonia and Denmark. Nematology 1:321-332.

Griffin, C. T., S. A. Joyce, I. Dix, A. M. Burnell, and M. J. Downes. 1994. Characterization of the entomopathogenic nematode Heterorhabditis (Nematoda: Heterorhabditidae) from Ireland and Britain by molecular and cross-breeding techniques and the occurrence of the genus in these islands. Fundamental and Applied Nematology 17:245-253.

Griffin, C. T., J. F. Moore, and M. J. Downes. 1991 Occurrence of insect parasitic nematodes (Steinernematidae, Heterorhabditidae) in the Republic of Ireland. Nematologica 37:92-100.

Hajek, A. E., M. L. McManus, and I. Delalibera, Jr. 2007. A review of introductions of pathogens and nematodes for classical biological control of insects and mites. Biological Control 41:1-13.

Hanski, I. 1991. Single-species metapopulations dynamics: concepts, models and observations. Pages 17-38 in M. Gilpin and I. Hanski, editors. Metapopulation dynamics: empirical and theoretical investigations. Academic Press, London, UK. 
Hominick, W. M. 2002. Biogeography. Pages 115-143 in R. Gaugler, editor. Entomopathogenic nematology. CABI Publishing, New Jersey, USA.

Huff, D. R., R. Peakall, and P. E. Smouse. 1993. RAPD variation within and among natural populations of outcrossing buffalograss (Buchloe dactyloides (Nutt) Engelm). Theoretical and Applied Genetics 86:927-934.

Kidd, N. A. C., and M. A. Jervis. 1997. The impact of parasitoids and predators on forest insect populations. Pages 49-68 in A. D. Watts, N. E. Stork, and M. D. Hunter, editors. Forests and insects. Chapman and Hall, London, UK.

Leather, S. R., K. R. Day, and A. N. Sailsbury. 1999. The biology and ecology of the large pine weevil, Hylobius abietis (Coleoptera: Curculionidae): a problem of dispersal? Bulletin of Entomological Research 89:3-16.

Louda, S. M., A. E. Arnett, T. A. Rand, and F. L. Russell. 2003. Invasiveness of some biological control insects and adequacy of their ecological risk assessment and regulation. Conservation Biology 17:73-82.

Millar, L. C., and M. E. Barbercheck. 2001. Interaction between endemic and introduced entomopathogenic nematodes in conventional-till and no-till corn. Biological Control 22:235-245

Minitab, Inc. 2000. MINITAB statistical software, release 14 for Windows. Minitab, Inc., State College, Pennsylvania, USA.

Norlander, G., H. Nordenhem, and H. Bylund. 1997. Oviposition patterns of the pine weevil Hylobius abietis. Entomologica Experimentalis et Applicata 85:1-9.

Organisation for Economic Co-operation and Development. 2003. Guidance for information requirements for regulation of invertebrates as biological control agents (IBCAs). Series on pesticides number 21. OECD Environmental Directorate (2004). 〈www.oecd.org/dataoecd/6/20/28725175.pdf〉

Orloci, L. 1978. Multivariate analysis in vegetation research. Junk, The Hague, The Netherlands.

Otsen, M., R. Hoekstra, M. E. Plas, J. B. Buntjer, J. A. Lenstra, and M. H. Roos. 2001. Amplified fragment length polymorphism analysis of genetic diversity of Haemochus concortus during selection for drug resistance. International Journal of Parasitology 31:1138-1143.

Parkman, J. P., J. H. Frank, K. B. Nguyen, and G. C. Smart, Jr. 1993. Dispersal of Steinernema scapterisci (Rhabditida: Steinernematidae) after inoculative applications for mole cricket (Orthoptera: Gryllotalpidae) control in pastures. Biological Control 3:226-232.

Parkman, J. P., J. H. Frank, T. J. Walker, and D. J. Schuster. 1996. Classical biological control of Scapteriscus spp. (Orthoptera: Gryllotalpidae) in Florida. Environmental Entomology 25:1415-1420.

Peakall, R., and P. E. Smouse. 2006. GENALEX 6: genetic analysis in Excel. Population genetic software for teaching and research. Molecular Ecology Notes 6:288-295.

Peters, A. 1996. The natural host range of Steinernema and Heterorhabditis spp. and their impact on insect populations. Biocontrol Science and Technology 6:389-402.

Poinar, G. O. 1986. Entomopathogous nematodes. Pages 95 121 in B. D. Franz, editor. Biological plant and health protection. Gustav Fischer Verlag, Stuttgart, Germany.

Rolston, A. N., C. Meade, and M. J. Downes. 2006. Analysis of populations of Steinernema feltiae and Heterorhabditis downesi from Bull Island, Ireland, using amplified fragment length polymorphism (AFLP). Journal of Nematology 38: 290.

Ryall, K. L., and L. Fahrig. 2006. Response of predators to loss and fragmentation of prey habitat: a review of theory. Ecology 87:1086-1093.

Salvato, P., A. Battisti, S. Concato, L. Masutti, T. Patarnello, and L. Zane. 2002. Genetic differentiation in the winter pine processionary moth (Thaumetopoea pityocampa-wilkinsoni complex) inferred by AFLP and mitochondrial DNA markers. Molecular Ecology 11:2435-2444.

Shields, E. J., A. Testa, J. M. Miller, and K. L. Flanders. 1999 Field efficacy and persistence of the entomopathogenic nematodes Heterorhabditis bacteriophora Oswego and $H$. bacteriophora $\mathrm{NC}$ on alfalfa snout beetle larvae. Environmental Entomology 28:128-136.

Simberloff, D., and P. Stiling. 1996. Risks of biological control. Biological Conservation 78:185-192.

Smits, P. H. 1996. Post-application persistence of entomopathogenic nematodes. Biocontrol Science and Technology 6 : 379-387.

Somasekhar, N., P. S. Grewal, E. A. B. De Nardo, and B. R. Stinner. 2002a. Non-target effects of entomopathogenic nematodes on the soil nematode community. Journal of Applied Ecology 39:735-744.

Somasekhar, N., P. S. Grewal, and M. G. Klein. 2002b. Genetic variability in stress tolerance and fitness among natural populations of Steinernema carpocapsae. Biological Control 23:303-310.

Sturhan, D. 1999. Prevalence and habitat specificity of entomopathogenic nematodes in Germany. Pages 123-132 in R. L. Gwynn, P. H. Smits, C. Griffin, R. U. Ehlers, N. Boemare, and J. P. Masson, editors. COST 819: Entomopathogenic nematodes. Application and persistence of entomopathogenic nematodes. Office for Official Publications of the European Communities, Luxembourg, Belgium.

Swihart, R. K., Z. Feng, N. A. Slade, D. M. Mason, and T. M. Gehring. 2001. Effects of habitat destruction and resource supplementation in a predator-prey metapopulation model. Journal of Theoretical Biology 210:287-303.

Symondson, W. O. C., K. D. Sunderland, and M. H Greenstone. 2002. Can generalist predators be effective biological control agents? Annual Review of Entomology 47:561-594.

Thomas, M. B., and A. J. Willis. 1998. Biocontrol: risky but necessary? Trends in Ecology and Evolution 13:325-329.

Tooley, P. W., E. D. Goley, M. M. Carras, and N. R. O Neill. 2002. AFLP comparisons among Claviceps africana isolates from the United States, Mexico, Africa, Australia, India and Japan. Plant Disease 86:1247-1252.

Travis, S. E., E. Proffitt, and K. Ritland. 2004. Population structure and interbreeding vary with successional stage in created Sparina alterniflora marshes. Ecological Applications 14:1189-1202.

Tzortzakakis, E. A., V. C. Blok, M. S. Phillips, and D. L. Trudgill. 1999. Variation in root-knot nematode (Meloidogyne spp.) in Crete in relation to control with resistant tomato and pepper. Nematology 1:499-506.

van Lenteren, J. C., D. Babendreier, F. Bigler, G. Burgio, H. M. T. Hokkanen, S. Kuske, A. J. M. Loomans, I Menzler-Hokkanen, P. C. J. van Rijn, M. B. Thomas, M. G Tommasini, and O. O. Zeng. 2003. Environmental risk assessment of exotic natural enemies used in inundative biological control. Biocontrol 48:3-38.

Vos, P., R. Hogerrs, M. Blekker, M. Reijans, T. Vandelee, M. Hornes, A. Frijterrs, J. Pot, J. Peleman, M. Kuiper, and M. Zabeau. 1995. AFLP: a new technique for DNA fingerprinting. Nucleic Acids Research 23:4407-4414.

Wainhouse, D., A. Ashburner, and B. Boswell. 2001. Reproductive development and maternal effects in the pine weevil Hylobius abietis. Ecological Entomology 26:655-661.

Wallace, H. R. 1954. The ecology of the insect fauna of pine stumps. Journal of Animal Ecology 22:154-171.

Weigel, D. A., J. T. Peterson, and P. Spruell. 2003. Introgressive hybridization between native cutthroat trout and introduced rainbow trout. Ecological Applications 13:38-50.

Woodring, J. L., and H. K. Kaya. 1988. Steinernematid and Heterorhabditid nematodes: a handbook of techniques. Cooperative Series Bulletin 331. Arkansas Agricultural Experiment Station, Fayetteville, Arkansas, USA. 